\title{
Análise espaço-temporal dos ventos no extremo norte da Planície Costeira do Rio Grande do Sul, Brasil
}

\author{
Gabriela Camboim ROCKETT ${ }^{1}$, Priscila TELLES ${ }^{2}$, Eduardo Guimarães BARBOZA ${ }^{3}$, Nelson Luiz \\ Sambaqui GRUBER ${ }^{3}$ \& Carlos Eduardo SIMÃO ${ }^{4}$
}

1 Programa de Pós-Graduação em Geociências, Universidade Federal do Rio Grande do Sul. Av. Bento Gonçalves, 9.500, CEP 91.540-000, Porto Alegre, RS, Brasil (gabriela.rockett@ufrgs.br).

2 Programa de Pós-Graduação em Engenharia Elétrica, Universidade Federal do Rio Grande do Sul. Av. Osvaldo Aranha, 103, CEP 90.035-190, Porto Alegre, RS, Brasil (priscilatelles3@gmail.com).

3 Centro de Estudos de Geologia Costeira e Oceânica, Instituto de Geociências, Universidade Federal do Rio Grande do Sul. Av. Bento Gonçalves, 9500, CEP 91.540-000, Porto Alegre, RS, Brasil (eduardo.barboza@ufrgs.br, nelson.gruber@ufrgs.br).

4 Programa de Pós-Graduação em Engenharia Oceânica, Fundação Universidade Federal do Rio Grande. Av. Itália km 8, CEP 96.203-900, Rio Grande, RS, Brasil (cadusimao@gmail.com).

Recebido em 04/2016. Aceito para publicação em 07/2017.

Versão online publicada em 21/10/2017 (www.pesquisasemgeociencias.ufrgs.br)

\begin{abstract}
Resumo - 0 transporte de partículas entre diferentes regiões é fortemente influenciado pela atividade dos ventos, o qual pode exercer grande influência na formação das paisagens litorâneas. Com o objetivo de caracterizar a dinâmica dos ventos no extremo norte da Planície Costeira do Rio Grande do Sul (RS), foram analisados dados históricos e anuais dos ventos (velocidade e direção) de quatro estações meteorológicas localizadas na região. Os resultados demonstram que na estação de Torres os ventos provenientes das direções $\mathrm{NE}$ e $\mathrm{S}$ são mais frequentes, e que os ventos das direções $\mathrm{W}$ e $\mathrm{N}$ são raros. Na estação SBTR/Aeroporto, os ventos do quadrante N-E são os mais frequentes (32\%), seguidos dos ventos provenientes das direções SW, SSW e S. Na estação da Lagoa Itapeva Central o padrão dos ventos se altera um pouco, prevalecendo as direções NE e SW, com ventos de maior intensidade provenientes da direção SW. Verificou-se uma variabilidade considerável na direção e frequência dos ventos no decorrer das estações do ano, apresentando maiores valores de intensidade durante o inverno. Com base nos dados obtidos para cada estação meteorológica, constatou-se que no extremo norte da Planície Costeira do RS os ventos de maiores intensidade (quadrante S-SW) são registrados na estação localizada mais ao sul (município de Arroio do Sal), mais próxima à base do Planalto Serra Geral, numa localidade em que as ocorrências coincidem com as direções livres de obstáculos orográficos. Apesar disso, as análises espaço-temporais evidenciaram que as diferentes localidades não possuem diferenças significativas nos padrões direcionais do vento considerando a unidade direcional como sendo o quadrante.
\end{abstract}

Palavras-chave: clima, estações meteorológicas, padrão de vento.

Abstract - SPATIAL-TEMPORAL ANALYSIS OF THE WINDS IN THE EXTREME NORTH OF Rio GRANDE DO SUl COASTAL Plain, BRAZil.The sediment transport between different regions is strongly influenced by wind activity, which can have great influence on the formation of coastal landscapes. Aiming to characterize the wind dynamic in the extreme north of Rio Grande do Sul (RS) Coastal Plain, historic and annual wind data (speed and direction) of four meteorological stations located in the region were analyzed in this study. Results show that in Torres station the winds that occur more often are from NE and S, and winds from W and N are rare. In the SBTR/Airport station, winds from the N-NE quadrant are the most frequent (32\%), followed by the winds from SW, SSW and S. In the Central Itapeva Lake station the wind pattern changes slightly, and the most frequent wind directions are NE and SW, with more intense winds coming from SW. It was verified also a variability in the winds directions and frequency during different seasons, with more intense winds during winter. Based on the wind data from each meteorological station, it was found that in the extreme north of RS Coastal Plain the greatest winds intensity (S-SW quadrant) occur at the station which is located further south (Arroio do Sal Municipality), which is closer to the Serra Geral scarps, where the wind direction coincides with the direction free of orographic obstacles. Nevertheless, the spatial-temporal analysis showed that the different localities do not have significant differences in wind directional patterns considering the directional unit as the quadrant.

Keywords: climate, meteorological stations, wind pattern. 


\section{Introdução}

O deslocamento do ar atmosférico se deve a diferenças de gradientes de pressão atmosférica entre duas regiões distintas, influenciadas por efeitos locais. Os movimentos das massas de ar são responsáveis pela geração de ventos em superfície, os quais se deslocam sempre de zonas de maior para as de menor pressão e, por sua vez, são responsáveis pelo transporte de partículas de areia e poeira de uma região para outra. Os ventos sofrem influências também do movimento de rotação da Terra, da força centrífuga ao seu movimento, bem como da topografia e consequente atrito com a superfície terrestre (Tubelis \& Nascimento, 1984). A velocidade do vento é influenciada pela distância da massa de ar da superfície, bem como da presença ou não de obstáculos (por exemplo: florestas, relevo acidentado e edificações). Quanto mais próximo da superfície, maior é o atrito da massa de ar com os obstáculos presentes e, portanto, a velocidade do vento é menor. Ao se afastar da superfície, em maior altitude, a velocidade do vento é maior.

0 conhecimento da direção predominante do vento, velocidade média e possíveis fenômenos cíclicos que ocorrem num local, fornecem informações importantes para fins científicos e de planejamento de atividades que dependam das condições do vento como, por exemplo, agricultura, obras de engenharia, energia, navegação, esportes náuticos e planejamento ambiental (ex.: Camargo \& Silva, 2002; Da Silva, 2007; Munhoz \& Garcia, 2008; Brito-Costa, 2009; Alves \& Silva, 2011; Costa \& Lyra, 2012; Morais et al., 2014).

A região nordeste da Planície Costeira do Rio Grande do Sul enquadra-se na zona temperada e, segundo Nimer (1977), seu clima pode ser definido como mesotérmico brando, superúmido, sem estação seca. A temperatura média nesta região é entre 22 e $24^{\circ} \mathrm{C}$, com precipitação acumulada anual entre 1250 e 1450 mm (INMET, 2015).

O clima do Rio Grande do Sul caracteriza-se por ser sazonal, e os ventos que afetam a região nordeste do Estado são basicamente o resultado da ação de dois sistemas de alta pressão que atuam na região: o Anticiclone do Atlântico Sul (AAS) e o Anticiclone Móvel Polar (AMP), segundo Nimer (1977). O Anticiclone do Atlântico Sul, originado em latitudes tropicais, gera uma massa tropical marítima, quente e úmida, enquanto o Anticiclone Polar, originado na Antártica, gera uma massa polar. Esta massa polar é responsável pela entrada periódica de frentes frias em direção ao norte, que ocorrem com maior frequência durante o inverno do que durante o verão (Homsi, 1978).

Grimm et al. (1998) afirmam que no litoral norte do RS as maiores altitudes do relevo são responsáveis pela estação mais chuvosa durante os meses de verão (gerando chuvas orográficas a partir das massas quentes atuantes neste período na região), enquanto no litoral médio e sul do RS o pico de chuvas se dá nos meses de inverno (gerado pela maior ocorrência de sistemas frontais neste período). A região Sul do Brasil é periodicamente afetada pelo fenômeno El Niño, responsável por distúrbios de repercussão global no sistema oceano/atmosfera. No Sul do Brasil, os eventos El Niño/ Oscilação Sul causam a manutenção de sistemas frontais persistentes na região, gerando anomalias no regime pluviométrico - frequentemente associados a uma maior pluviosidade (Kousky \& Cavalcanti, 1984; Kim, 1998).

Segundo Reis \& Berlato (1972), para todas as regiões climáticas do RS, as direções predominantes dos ventos são NE, E e SE, e as velocidades médias mais elevadas ocorrem nos meses de primavera e as menores no outono. Estudos para caracterização dos ventos em regiões específicas do RS (principalmente nas regiões central e costeira) já foram realizados (Silva et al., 1997; Braga \& Krusche, 1998; Tomazelli, 1993; Camargo \& Silva, 2002; Martinho et al., 2010; Favera et al., 2012; Fuentes et al., 2013), e mostram peculiaridades nas diferentes regiões.

No contexto da Planície Costeira do Rio Grande do Sul (PCRS), o vento é um agente modelador da paisagem com grande relevância, responsável por significativos processos geomorfológicos que atuam na mesma (Tomazelli, 1990, 1993). A grande extensão dos campos de dunas presentes na PCRS mostra que a atuação dos ventos na região é significativa, atrelado à disponibilidade de sedimentos trazidos pela ação de ondas e correntes oceânicas. Um estudo para determinar os padrões de ventos na PCRS foi realizado por Tomazelli (1993), utilizando-se séries históricas de dados de três estações meteorológicas distribuídas ao longo da costa do RS - municípios de Torres, Imbé e Rio Grande -, indicando que o vento mais frequente ao longo da costa é o vento proveniente de NE. Porém, diferenças significativas entre as estações podem ser observadas, não só pela distância entre as mesmas (de algumas centenas de quilômetros), mas também pelas diferenças topográficas entre as três diferentes regiões. Os dados da estação meteorológica localizada em Torres, no extremo norte da PCRS, demonstram a influência que o Planalto da Serra Geral exerce sobre os ventos locais (Tomazelli, 1993; Martinho, 2008). Dentro deste con- 
texto, este trabalho tem por objetivo caracterizar a dinâmica dos ventos atuantes no extremo norte da PCRS, e assim, fornecer subsídios para o planejamento ambiental da região.

\section{2 Área, materiais e métodos}

Este estudo foi conduzido através da análise de séries de dados de três estações meteorológicas localizadas no extremo norte da PCRS.

\subsection{Localização da área}

A PCRS estende-se por $620 \mathrm{~km}$ desde o Arroio Chuí (extremo sul) até a barra do Rio Mampituba (extremo norte), com larguras que variam entre 20 $\mathrm{km}$ e $80 \mathrm{~km}$ (Tomazelli et al., 2000; Dillenburg et al., 2009), com orientação NE-SW. O litoral norte da PCRS difere-se das demais regiões pela maior proximidade da linha de costa às escarpas do Planalto Serra Geral (a oeste), com distância de aproximadamente $25-30 \mathrm{~km}$ (Fig. 1). Esta config- uração do relevo confere diferenciações no clima da porção norte da PCRS. No município de Torres, ocorrem afloramentos rochosos das formações Serra Geral e Botucatu na praia, os quais dão origem a falésias, feições estas que configuram peculiaridade na paisagem da região.

\subsection{Materiais}

A análise espaço-temporal dos ventos da área de estudo se deu a partir dos dados de quatro estações meteorológicas, as quais estão localizadas de norte para o sul, respectivamente: estação de Torres, pertencente ao Instituto Nacional de Meteorologia (INMET); estação Lagoa Itapeva Norte; estação Permissionária de Telecomunicação e Tráfego Aéreo de Torres (SBTR), pertencente ao Aeroporto da cidade - localizadas no município de Torres; e estação da Lagoa Itapeva central - situada no município de Arroio do Sal. A localização espacial das quatro estações meteorológicas analisadas neste estudo consta na figura 1.
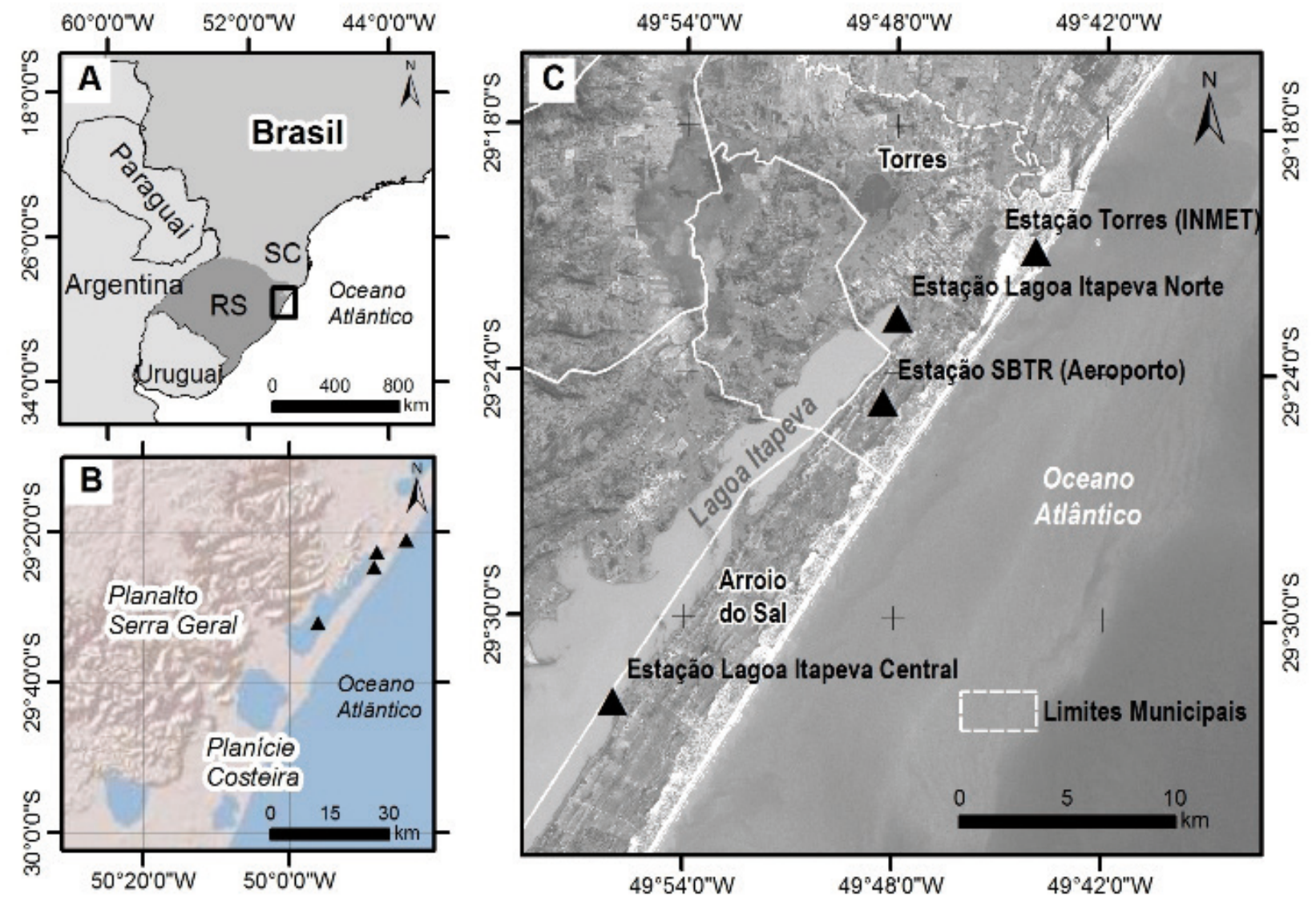

Figura 1. Contextualização espacial da área de estudo e localização das quatro estações meteorológicas analisadas (triângulos pretos), no extremo norte da Planície Costeira do Rio Grande do Sul. A) Escala continental; B) Escala regional; C) Escala local. Imagem do satélite SPOT, banda pancromática, 2005.

Figure 1. Spatial contextualization of the study area and location of the four meteorological stations analyzed (black triangles), in the extreme north of Rio Grande do Sul Coastal Plain. A) Continental scale; B) Regional scale; C) Local scale. SPOT satellite image, panchromatic band, 2005. 
A série de dados de velocidade e direção do vento da estação meteorológica de Torres compreende o período de monitoramento de 14 anos, de maio de 2002 a abril de 2015. Os dados de velocidades e direção do vento para esta estação são obtidos através de três medições diárias. Para a estação Permissionária de Telecomunicação e Tráfego Aéreo de Torres (SBTR/Aeroporto) foi utilizada uma série de dados de velocidade e direção do vento de 11 anos, que compreende o período de janeiro de 2004 a maio de 2014. Os dados de velocidade e direção do vento desta estação meteorológica são obtidos através de medições diárias.

Quanto às estações meteorológicas instaladas nas margens leste e norte da Lagoa Itapeva, foram utilizados os dados disponíveis já tratados do Projeto "Comportamento hidrodinâmico da Lagoa Itapeva (Litoral Norte do RS) e seu efeito potencial sobre comunidades planctônicas", desenvolvido pelo Instituto de Pesquisas Hidráulicas da Universidade Federal do Rio Grande do Sul - IPH/UFRGS (Cardoso, 2001; Lopardo, 2002; Cardoso et al., 2003). Os dados de velocidade e direção do vento destas estações são limitados, sendo oriundos de coletas sazonais no período de um ano, entre dezembro de 1998 e dezembro de 1999.

\subsection{Métodos}

Para a análise espacial da frequência e intensidade dos ventos da área de estudo, foram utilizadas medidas diárias de velocidade e direção das estações meteorológicas de Torres e SBTR/Aeroporto, e os dados horários já tratados da estação Lagoa Itapeva Central (conforme Cardoso, 2001 e Cardoso et al., 2003). Os dados obtidos de direção e velocidade dos ventos foram organizados em planilhas eletrônicas, para posterior análise. Os dados das séries históricas (Torres e Aeroporto) foram devidamente consistidos e, para estes, foram realizadas análises estatísticas para gerar o diagrama de ocorrência conjunta. Nestas análises, os dados foram agrupados quanto a sua ocorrência dentro de 16 direções e 8 intervalos de intensidade (Pearce \& Walker, 2005; ASA, 2006; Martinho, 2008).

Outra análise realizada foi a representação gráfica por meio da rosa dos ventos, a qual apresenta a distribuição da ocorrência percentual dos ventos por direções. A ferramenta utilizada para análise estatística e confecção dos gráficos de frequência e intensidade dos ventos foi o software WRPLOT (www.lakes-environmental.com). Para a série histórica de dados mais longa e consistente (estação meteorológica de Torres), fez-se também a análise sazonal dos ventos atuantes, a fim de obter maiores detalhes sobre a variação dos ventos da região nas diferentes épocas do ano.

Foi realizada também a análise sazonal do ano de 1999 para a estação Torres, para possibilitar a comparação espacial dos ventos desta estação meteorológica com os dados existentes da estação Lagoa Itapeva Norte para o mesmo ano (Lopardo, 2002). Foi utilizada a maior quantidade de dados de ventos disponíveis para a região.

Os dados das estações Torres e SBTR/Aeroporto foram também analisados estatisticamente no software WRPLOT (distribuição de frequências dos dados - distribuição normal), quanto a sua ocorrência média mensal para as variáveis direção e intensidade. As séries de intensidades médias dos ventos para ambas as estações foram plotadas em um gráfico de linhas para comparação do comportamento temporal desta variável no tempo, para o período de 2002 a 2015.

Os dados da estação de Torres (INMET) foram analisados mais profundamente quanto à frequência direcional dos ventos registrados nesta estação ao longo dos meses do ano. Foi escolhida para esta análise a estação meteorológica de Torres por esta apresentar três medições diárias durante a série histórica escolhida, sem falhas de registro. Para fins de análise de remobilização de sedimentos pelo vento, a análise de frequência direcional limitou-se à analise dos ventos com velocidades acima de $5 \mathrm{~m} / \mathrm{s}$, velocidade mínima do vento, registrada a $10 \mathrm{~m}$ de altura, para manter a areia em saltação, conforme Tomazelli (1993), considerando as características da areia da região estudada.

\section{Resultados}

A tabela 1 apresenta o diagrama de ocorrência conjunta de direção e velocidade dos ventos registrados na estação de Torres, no período de maio de 2002 até abril de 2015. 0 número total de observações desta estação é 14.192. Na rosa dos ventos obtida a partir dos dados diários da estação de Torres (Fig. 2), percebe-se que os ventos provenientes das direções NE e $\mathrm{S}$ ocorrem com maior frequência, enquanto ventos das direções $\mathrm{W}$ e $\mathrm{N}$ são raros.

A análise dos dados mostra que o vento mais frequente nesta estação provém de NE (23,9\%), seguido de ventos de $S(16,2 \%)$. As velocidades dos ventos de NE variam de 0,1 a 5,6 m/s em $20,5 \%$ dos casos. Os ventos de $S$ também variam no mesmo intervalo de velocidade em $12,5 \%$ das ocorrências. 
As calmarias são bastante frequentes, atingindo 32\% nesta estação meteorológica. Ventos de E e de SW possuem frequências de 8,2 e 7\%, respectivamente. Os ventos de $\mathrm{E}$ atingem velocidades menores que $3,0 \mathrm{~m} / \mathrm{s}$ em $6,4 \%$ dos casos, enquanto $2,5 \%$ dos ventos de SW possuem velocidades maiores, entre 3,0 e 5,6 m/s. Ventos de W são pouco frequentes na estação de Torres $(1,7 \%$ de frequência, na maioria das vezes com velocidade de até 3,0 m/s). Em menor frequência ocorrem os ventos de maiores intensidades, acima de $5,6 \mathrm{~m} / \mathrm{s}$, provenientes principalmente de $S(3,62 \%)$ e $\mathrm{NE}$ $(3,3 \%)$. Para o período analisado, os ventos com intensidades superiores a $7 \mathrm{~m} / \mathrm{s}$ provém majoritariamente de $S(0,79 \%)$, enquanto ventos acima deste valor provenientes de NE ocorrem apenas em $0,37 \%$ das ocorrências. Ventos de intensidades superiores a $14,3 \mathrm{~m} / \mathrm{s}$ não foram registrados nesta estação durante o período analisado.

Tabela 1. Diagrama de ocorrência conjunta de velocidade e direção dos ventos na estação meteorológica de Torres, no período de 2002 a 2015.

Table 1. Diagram of joint occurrence of wind speed and direction at the Torres meteorological station, in the period 2002-2015.

\begin{tabular}{|c|c|c|c|c|c|c|c|c|}
\hline \multirow{2}{*}{$\begin{array}{c}\text { Direção } \\
\text { Vento }\end{array}$} & \multicolumn{7}{|c|}{ Intervalos de Velocidades (m/s) } & \multirow{2}{*}{ Total (\%) } \\
\hline & $0,1-3,0$ & $3,0-5,6$ & $5,6-7,0$ & $7,0-8,7$ & $8,7-11,3$ & $11,3-14,3$ & 14,3 & \\
\hline $\mathrm{N}$ & 3,11 & 0,25 & 0,07 & 0 & 0 & 0,01 & 0 & 3,43 \\
\hline NNE & 0,01 & 0 & 0 & 0 & 0 & 0 & 0 & 0,01 \\
\hline $\mathrm{NE}$ & 11,64 & 8,87 & 2,97 & 0,36 & 0 & 0,01 & 0 & 23,94 \\
\hline ENE & 0,01 & 0,01 & 0 & 0 & 0 & 0 & 0 & 0,02 \\
\hline E & 6,39 & 1,59 & 0,18 & 0,01 & 0 & 0 & 0 & 8,17 \\
\hline ESE & 0 & 0 & 0 & 0 & 0 & 0 & 0 & 0 \\
\hline SE & 4,44 & 1,21 & 0,3 & 0,06 & 0,01 & 0 & 0 & 6,01 \\
\hline SSE & 0 & 0 & 0 & 0 & 0 & 0 & 0 & 0 \\
\hline$S$ & 7,55 & 4,98 & 2,84 & 0,5 & 0,28 & 0,01 & 0 & 16,16 \\
\hline SSW & 0 & 0 & 0 & 0 & 0 & 0 & 0 & 0 \\
\hline SW & 3,39 & 2,48 & 0,85 & 0,15 & 0,04 & 0,01 & 0 & 6,92 \\
\hline WSW & 0,01 & 0,01 & 0 & 0 & 0 & 0 & 0 & 0,01 \\
\hline W & 1,22 & 0,26 & 0,13 & 0,06 & 0,03 & 0,01 & 0 & 1,71 \\
\hline WNW & 0 & 0 & 0 & 0 & 0 & 0 & 0 & 0 \\
\hline NW & 1,21 & 0,13 & 0,01 & 0 & 0,01 & 0 & 0 & 1,36 \\
\hline NNW & 0 & 0 & 0 & 0 & 0 & 0 & 0 & 0 \\
\hline Calma & - & - & - & - & - & - & - & 32,24 \\
\hline
\end{tabular}

A tabela 2 apresenta o diagrama de ocorrência conjunta para a direção e velocidade dos ventos registrados na estação Permissionária de Telecomunicação e Tráfego Aéreo de Torres (SBTR/ Aeroporto), no período de janeiro de 2004 a maio de 2014. 0 número total de observações desta estação é 1.241.

Na figura 3 consta a rosa dos ventos obtida a partir dos dados da Estação SBTR/Aeroporto, na qual observa-se o comportamento diferenciado do vento, predominando ventos de ENE e de E, com frequências de 11,7 e 11,3\%, respectivamente, seguido do vento NE, com 9,3\% de frequência. Juntos, os ventos provenientes deste quadrante somam $32 \%$ da frequência e são predominantes em relação às demais direções. 0 vento ENE ocorre em diferentes intensidades de velocidades (entre 0,1 e $14,3 \mathrm{~m} / \mathrm{s}$ ), destacando-se as velocidades mais al- tas, entre 7,0 e 8,7 m/s em 2,9\% das ocorrências, e velocidade entre 8,7 e $11,3 \mathrm{~m} / \mathrm{s}$ em $1,5 \%$ das ocorrências. Ventos de E são frequentes também, porém a intensidade dos mesmos é menor, com velocidades variando majoritariamente ente 0,1 e $5,6 \mathrm{~m} / \mathrm{s}$ ( $9,7 \%$ das ocorrências), assim como os ventos de NE $(7,5 \%$ das ocorrências com velocidades até $5,6 \mathrm{~m} / \mathrm{s}$ ).

Os ventos de SW, de SSW e de S também possuem frequências consideráveis $(8,5 \%, 7,9 \%$ e $7,7 \%$, respectivamente), enquanto os ventos provenientes das regiões $\mathrm{NW}, \mathrm{N}, \mathrm{W}$ e SE exercem pouca influência na região. Nesta estação, as calmarias não são tão frequentes quanto na estação de Torres $(7,3 \%)$, e ventos de direções WNW, NW e SE são raros $(<4 \%$ de frequência).

Com baixa frequência, ventos com velocidades superiores a 11,3 m/s foram registrados nes- 
ta estação meteorológica, sendo estes provenien- respectivamente). tes de $\mathrm{E}$ e de ENE (com 0,1\% e 0,2\% de frequência,

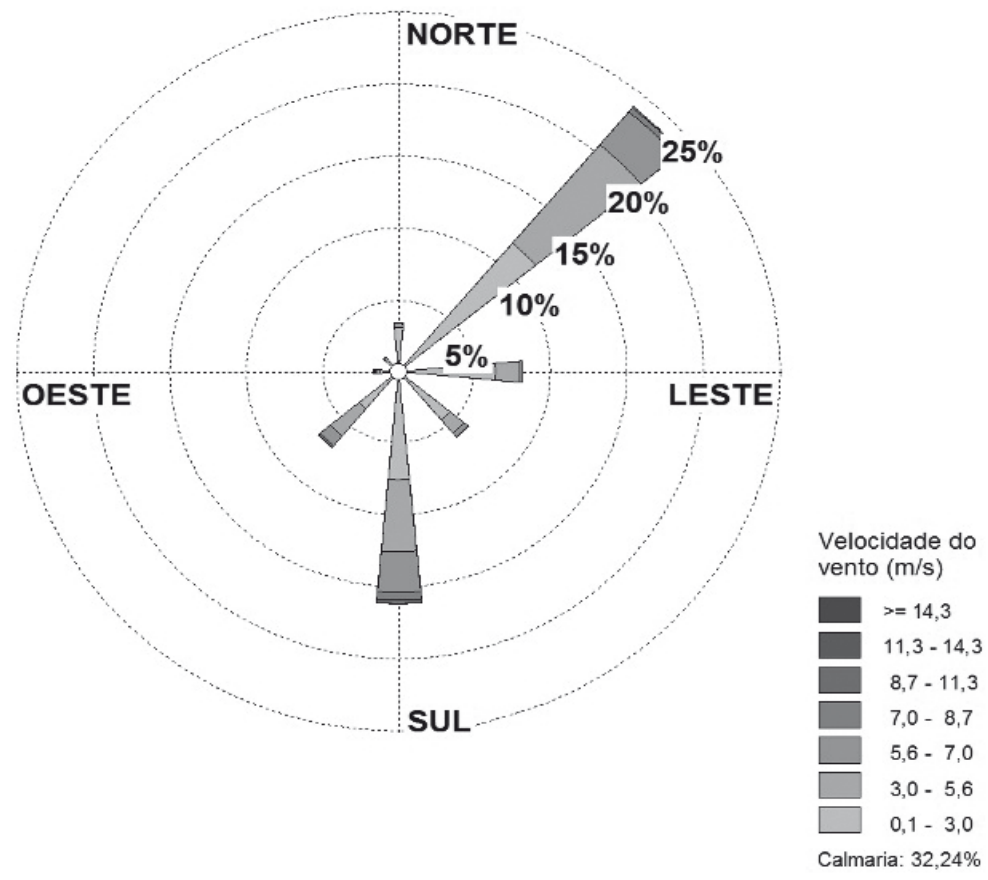

Figura 2. Rosa dos ventos mostrando a direção, velocidade e frequência dos ventos para a estação meteorológica de Torres (2002-2015), utilizando o software WRPLOT.

Figure 2. Wind rose showing direction, frequency and velocity of winds at Torres meteorological station (2002-2015), using the WRPLOT software.

Tabela 2. Diagrama de ocorrência conjunta velocidade e direção dos ventos na estação meteorológica SBRT/Aeroporto, no período de 2004 a 2014.

Table 2. Diagram of joint occurrence of wind speed and direction at the SBTR/Airport meteorological station, in the period 20042014.

\begin{tabular}{lccccccccc}
\hline \multicolumn{1}{c}{ Direção } & \multicolumn{7}{c}{ Intervalos de Velocidades (m/s) } & Total (\%) \\
\cline { 2 - 8 } \multicolumn{1}{c}{ Vento } & $\mathbf{0 , 1 - 3 , 0}$ & $\mathbf{3 , 0 - 5 , 6}$ & $\mathbf{5 , 6 - 7 , 0}$ & $\mathbf{7 , 0 - 8 , 7}$ & $\mathbf{8 , 7 - 1 1 , 3}$ & $\mathbf{1 1 , 3 - 1 4 , 3}$ & $\mathbf{1 4 , 3}$ & \\
\hline N & 2,58 & 1,37 & 0 & 0,08 & 0,08 & 0 & 0 & 4,11 \\
NNE & 3,95 & 3,63 & 0,56 & 0,08 & 0 & 0 & 0 & 8,22 \\
NE & 2,5 & 5 & 0,81 & 0,73 & 0,32 & 0 & 0 & 9,35 \\
ENE & 1,69 & 3,3 & 2,1 & 2,9 & 1,53 & 0,08 & 0,08 & 11,68 \\
E & 3,47 & 6,21 & 1,05 & 0,48 & 0 & 0 & 0,08 & 11,28 \\
ESE & 1,53 & 2,1 & 0,08 & 0 & 0,08 & 0 & 0 & 3,79 \\
SE & 1,29 & 1,05 & 0,08 & 0 & 0,08 & 0 & 0 & 2,5 \\
SSE & 1,45 & 1,93 & 0 & 0,08 & 0 & 0 & 0 & 3,47 \\
S & 1,37 & 4,35 & 1,21 & 0,81 & 0 & 0 & 0 & 7,74 \\
SSW & 1,37 & 3,3 & 1,37 & 1,37 & 0,48 & 0 & 0 & 7,9 \\
SW & 3,22 & 3,38 & 1,21 & 0,65 & 0 & 0 & 0 & 8,46 \\
WSW & 2,5 & 1,61 & 0,24 & 0,56 & 0,08 & 0 & 0 & 5 \\
W & 1,93 & 0,81 & 0,4 & 0,24 & 0 & 0 & 0 & 3,38 \\
WNW & 0,73 & 0,16 & 0,08 & 0 & 0 & 0 & 0 & 0,97 \\
NW & 1,61 & 0,32 & 0,08 & 0 & 0 & 0 & 0 & 2,02 \\
NNW & 2,42 & 0,48 & 0 & 0 & 0 & 0 & 0 & 2,9 \\
Calmarias & - & - & - & - & - & - & - & 7,25 \\
\hline
\end{tabular}




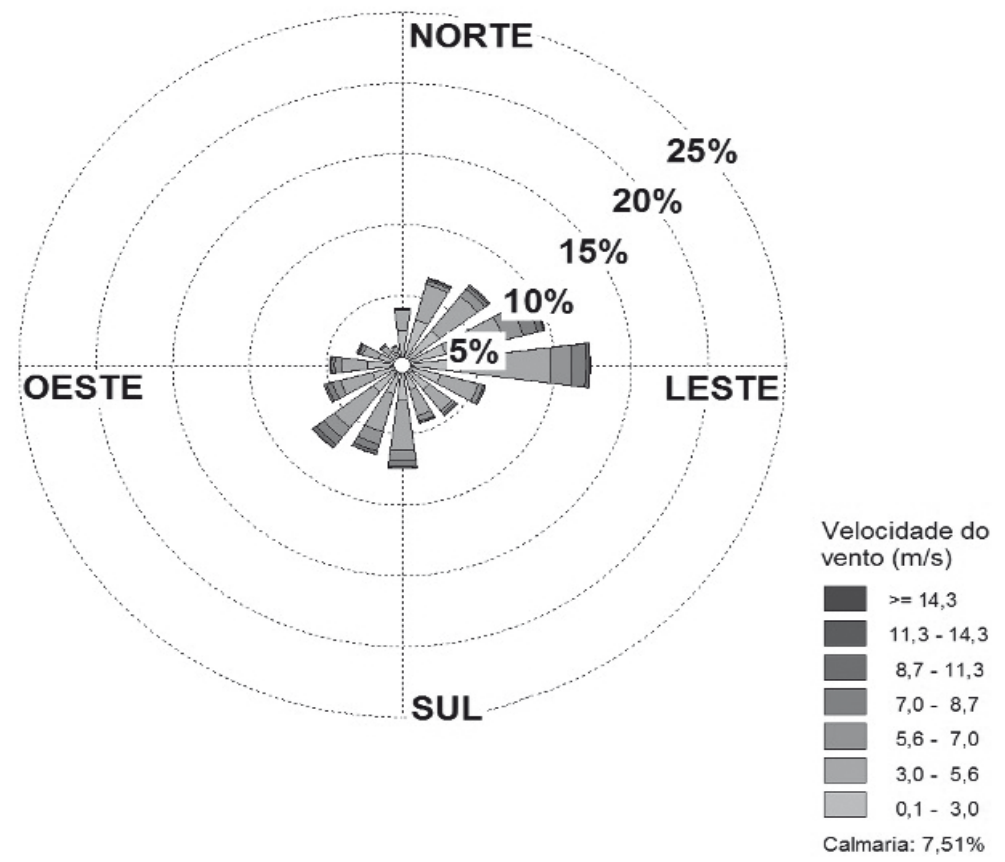

Figura 3. Rosa dos ventos mostrando a direção, frequência e velocidade dos ventos para a estação meteorológica SBTR/Aeroporto (2004-2014), utilizando o software WRPLOT.

Figure 3. Wind rose showing direction, frequency and velocity of winds at SBTR/Airport meteorological station (2004-2014), using the WRPLOT software.

A rosa dos ventos referente à estação meteorológica localizada mais ao sul da área de estudo, estação da Lagoa Itapeva Central, consta na figura 4. Nesta estação o padrão NE-S se altera para NE-SW. Ventos de até $17,5 \mathrm{~m} / \mathrm{s}$ são observados na direção SW; no entanto os ventos mais frequentes permanecem como sendo de NNE e NE $(16 \%$ e $13 \%$ respectivamente), como nas demais estações. Estes ventos, apesar de mais frequentes, não atingem velocidades tão altas quanto os de SW.

Esta estação meteorológica é importante pela sua localização mais ao sul da área de estudo, estando mais próxima às escarpas do planalto Serra Geral que as demais estações, numa região próxima ao vale do rio Três Forquilhas, que deságua na porção oeste da Lagoa Itapeva. Apesar da escassez dos dados (apenas um ano), as medições demonstram peculiaridades importantes registradas neste local, que em conjunto com os dados das demais estações permitem-nos fazer uma interpretação.

A tabela 3 apresenta a análise estatística descritiva dos dados referentes ao período de monitoramento das estações meteorológicas de Torres e da SBTR/Aeroporto. Observa-se, a partir da análise da velocidade média mensal, que os meses de primavera (setembro, outubro, novembro e dezembro) e verão (dezembro, janeiro, fevereiro e março) são os que possuem as maiores velocid- ades médias, enquanto no período compreendido entre o final do outono e início do inverno (maio, junho e julho) as velocidades são mais baixas.

A figura 5 mostra um gráfico comparativo de velocidade média mensal durante o período de monitoramento das estações de Torres e da SBTR/ Aeroporto. De forma geral, observa-se que a velocidade do vento sofre grandes variações no decorrer do período analisado, e que as duas estações apresentam um perfil semelhante. A velocidade média máxima na estação de Torres é igual a 3,66 m/s, no ano de 2006, e na estação Aeroporto, a velocidade média máxima foi igual a $5,44 \mathrm{~m} / \mathrm{s}$.

Os resultados da análise sazonal baseada na série temporal de dados mais consistente, de janeiro de 2002 a dezembro de 2015 (estação Torres), mostram que apesar da direção do vento de maior frequência ser NE neste local, verifica-se que há uma variação considerável na direção e frequência dos ventos durante as diferentes estações do ano (Fig. 6). De forma geral, observa-se o predomínio de ventos provenientes das direções NE e $\mathrm{S}$ nas quatro estações do ano, caracterizando um regime de ventos bimodal nesta estação meteorológica, com ventos de S frequentes ao longo do ano (aumentando pouco sua frequência durante o inverno e a primavera), enquanto que os ventos de NE possuem sua frequência bastante aumentada durante a primavera e o verão. 




Figura 4. Rosa dos ventos mostrando a direção, frequência e velocidade dos ventos para a estação meteorológica Lagoa Itapeva Central (de dezembro de 1998 a setembro de 1999), adaptado de Martinho (2008), baseado em dados de Cardoso (2001) e Cardoso et al. (2003).

Figure 4. Wind rose showing direction, frequency and velocity of winds at Itapeva lake meteorological station (from December 1998 to September 1999), adapted from Martinho (2008), based in original data from Cardoso (2001) and Cardoso et al. (2003).

Tabela 3. Velocidades médias para cada mês do ano das estações meteorológicas de Torres e da SBTR/Aeroporto. Table 3. Monthly average wind speed of Torres and SBTR/Airport meteorological stations.

\begin{tabular}{lcc}
\hline \multirow{2}{*}{ Mês } & \multicolumn{2}{c}{ Velocidade média do vento $(\mathrm{m} / \mathbf{s})$} \\
\cline { 2 - 3 } & Torres & SBTR (Aeroporto) \\
\hline Janeiro & 2,35 & 3,37 \\
Fevereiro & 2,12 & 3,47 \\
Março & 2,13 & 3,22 \\
Abril & 1,89 & 2,89 \\
Maio & 1,8 & 2,83 \\
Junho & 1,42 & 2,64 \\
Julho & 1,62 & 3,06 \\
Agosto & 2,15 & 3,4 \\
Setembro & 2,67 & 3,91 \\
Outubro & 2,75 & 4,3 \\
Novembro & 3,01 & 4,31 \\
Dezembro & 2,69 & 3,84 \\
\hline
\end{tabular}

No verão a direção principal dos ventos é a NE (28\% de frequência), seguidos de ventos S (14\%) de E (10\%). Os ventos de NE mais intensos são mais frequentes neste período, totalizando $4 \%$ das ocorrências acima de $5,6 \mathrm{~m} / \mathrm{s}$, seguidos de ventos de $\mathrm{S}$, com $2,2 \%$ das ocorrências. Durante o outono, há uma diversificação nas direções de proveniên- cia dos ventos, sendo que os ventos provenientes da direção $S$ passam a ser os mais frequentes (14\%) e mais intensos $(3,1 \%$ das ocorrências de ventos acima de $5,6 \mathrm{~m} / \mathrm{s}$ ), seguidos de ventos $\mathrm{NE}$ e SW $(0,9 \%$ e $1,5 \%$ de ocorrência de ventos com velocidades acima de 5,6 m/s, respectivamente). Durante o inverno, os ventos mais frequentes são 
os provenientes das direções NE (18\%), S (17\%) e SW (9\%), sendo que os ventos mais intensos ocorrem em maior frequência no quadrante S-SW (S $4,8 \%$ e SW 1,5\% das ocorrências com velocidades acima de $5,6 \mathrm{~m} / \mathrm{s}$, e NE 1,8\%). Já durante a primavera a direção predominante do vento passa a ser a NE, chegando a ter $35 \%$ de frequência, seguidos dos ventos de S (18\%) e E (10\%). Nesta estação do ano, há maior frequência de ventos mais intensos de NE (7\% com velocidades superiores a 5,6 $\mathrm{m} / \mathrm{s})$, seguidos dos ventos de S e SW $(4,4 \%$ e $1 \%$ das ocorrências com velocidades superiores a 5,6 $\mathrm{m} / \mathrm{s})$.



Figura 5. Variação da velocidade média mensal do vento para as estações meteorológicas de Torres e SBTR/Aeroporto (20022015).

Figure 5. Monthly average wind speed variation for Torres and SBTR/Airport meteorological stations (2002-2015).

Os dados mostram que ventos com intensidades superiores a $11,3 \mathrm{~m} / \mathrm{s}$ foram registrados durante os meses de inverno e primavera, e estes ventos mais intensos provém do quadrante S-SW (W e SW, respectivamente), indicando a atuação intensa dos sistemas frontais no período. Durante o outono, ventos com velocidades superiores a 11,3 $\mathrm{m} / \mathrm{s}$ foram registrados também nesta série histórica; porém, nesta estação do ano são provenientes das direções NE e S. Durante o verão, só há registro de ventos de velocidades inferiores à 11,3 m/s. A tabela 4 mostra a frequência de ventos mais intensos (velocidade $>5,6 \mathrm{~m} / \mathrm{s}$ ) nas diferentes estações do ano, para a estação de Torres. Observa-se que os ventos de $\mathrm{S}$ mais intensos possuem frequências significativas em todas as estações do ano, e ventos de NE mais intensos predominam nos meses de primavera e verão.

A análise da variação espaço-temporal sazonal de ventos para a região foi realizada com os dados disponíveis para as estações meteorológicas de Torres e Lagoa Itapeva Norte para o ano de 1999 (Fig. 7 e 8). Os resultados da estação de Torres (Fig. 7) mostram que, no verão do ano de 1999, os ventos mais frequentes foram de NE ( $25 \%$ da frequência), e de E ( $24 \%$ da frequência), sendo que os ventos de NE foram menos intensos que os de E (intensidades superiores a $5,6 \mathrm{~m} / \mathrm{s}$ corresponderam a apenas $0,86 \%$ dos ventos de NE e 2,58\% dos ventos de E). Ainda neste período do ano, os ventos de $\mathrm{S}$ foram pouco frequentes (9\%), porém em $2,1 \%$ possuíam intensidades superiores a $5,6 \mathrm{~m} / \mathrm{s}$. Durante a primavera, os ventos mais frequentes foram de NE (35\% da frequência), seguidos dos ventos de E (18\% da frequência) e SW (11\% da frequência). Os ventos de maiores intensidades (superiores a $5,6 \mathrm{~m} / \mathrm{s}$ ) nessa estação do ano, foram os de NE (5,8\% das ocorrências), seguidos dos ventos de SW $(2,5 \%$ das ocorrências). Durante o inverno, os ventos provenientes das direções NE continuaram sendo os mais frequentes (18\%), seguidos de ventos de SW (11\%) e W (11\%). 0 quadrante S-SW, apesar de variações nas direções, é o quadrante com maiores frequências de ventos, e deste quadrante são provenientes os ventos de maiores intensidades no inverno, $\mathrm{S}(2,5 \%)$ e SW $(2,1 \%)$. Ventos de NE com maiores intensidades correspondem a 1,8\% de frequência. Durante o outono, há uma diversificação nas direções de proveniência dos ventos, sendo que os ventos provenientes das direções $\mathrm{E}$ e $\mathrm{W}$ são os mais frequentes (14\% e 13\% respectivamente), e as direções W e S são marcadas pela ocorrência dos ventos mais intensos $(3,67 \%$ e $1,1 \%$ da fre- 
quência respectivamente).

Para o ano de 1999 na estação de Torres, os dados mostram que ventos com intensidades superiores a $10 \mathrm{~m} / \mathrm{s}$ ocorrem durante os meses de outono e inverno, sendo estes provenientes do quadrante $\mathrm{S}-\mathrm{W}$, indicando a atuação de sistemas frontais.
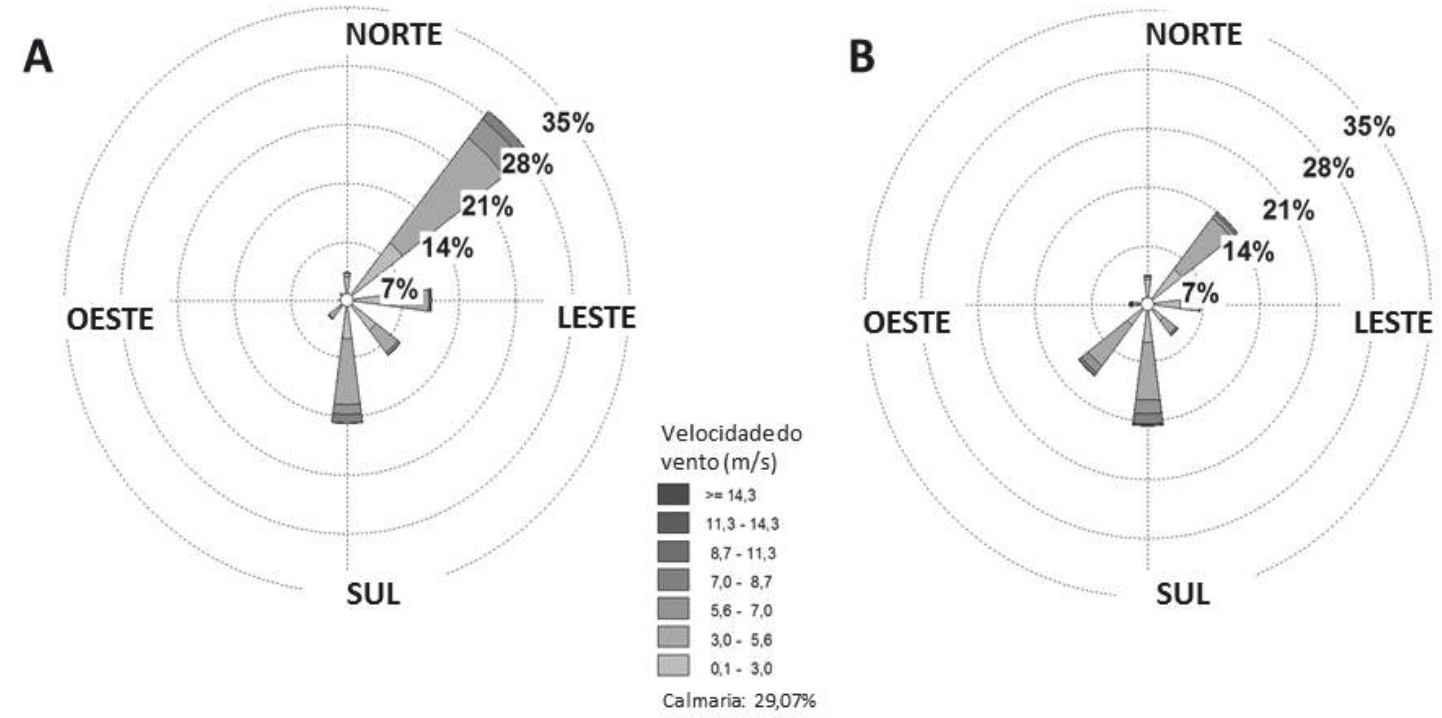

Velocidadedo vento $(\mathrm{m} / \mathrm{s})$

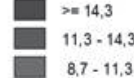

$8,7-11,3$

$5,7.70$

$5,6-7,0$
$3,0 \cdot 5,6$

$0,1 \cdot 3,0$

Calmaria: $42,20 \%$



Velocidadedo vento $(\mathrm{m} / \mathrm{s})$

$\square>14,3$

$11,3 \cdot 14,3$
$8,7-11,3$

$8,7-11,3$
$7,0-8,7$

$5,6-7,0$

$3,0 \cdot 5,6$

$0,1 \cdot 3,0$

Calmaria: $38,25 \%$

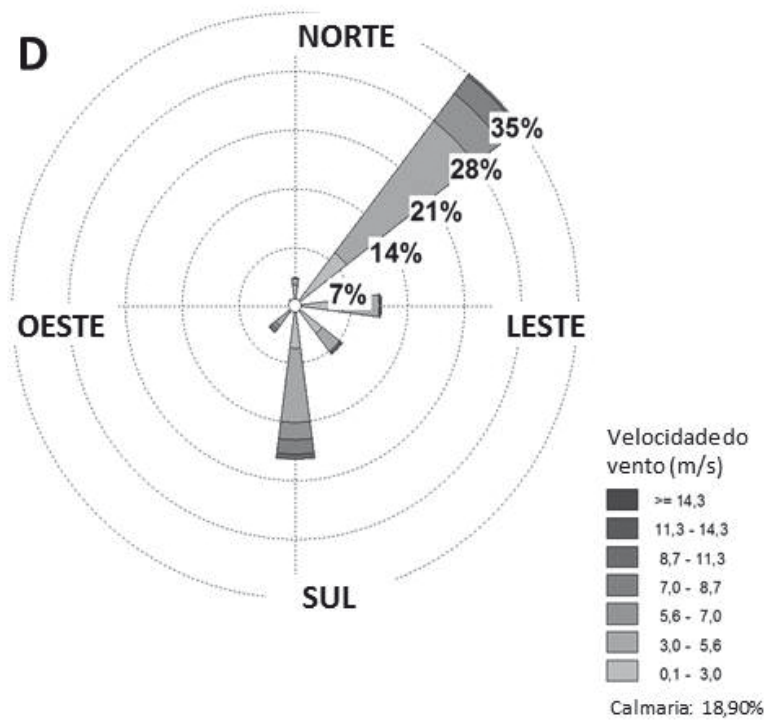

Figura 6. Rosa dos ventos mostrando a variação na direção e na frequência dos ventos nas quatro estações do ano na estação meteorológica de Torres (2002-2015). A) Verão; B) Outono; C) Inverno; D) Primavera.

Figure 6. Wind rose showing variations in direction, frequency and velocity of winds during the four annual seasons at the Torres meteorological station (2002-2015). A) Summer; B) Autumn; C) Winter; D) Spring.

A partir dos dados de Lopardo (2002), podese comparar os resultados da análise sazonal obtidos da estação de Torres (mais ao norte da área de estudo) em 1999 com os dados da estação da Lagoa Itapeva Norte (distante $7 \mathrm{~km}$ a sudoeste da estação de Torres) para o mesmo ano, conforme figura 8. Os resultados dessa estação mostram que, no verão do ano de 1999, os ventos mais frequentes foram do quadrante N-NE (NE 15\%, NNE $13 \%$ e ENE 18\%). As demais direções não apresentaram ocorrência significativa. No período de outono a componente de $\mathrm{N}$ representou aproximadamente $19 \%$ das ocorrências seguida dos ventos do quadrante $S-W$, que somaram aproximadamente $33 \%$ das ocorrências. No inverno a componente SW foi a de maior frequência, com quase $28 \%$ das ocorrências, seguido da direção N bem expressiva, com aproximadamente $18 \%$ das ocorrências. Na primavera os ventos do quadrante $\mathrm{N}$-E foram os mais significativos, somando aproximadamente $60 \%$ das ocorrências (NE 19\%, NNE $13 \%, \mathrm{~N} 17,5 \%$, ENE 10\%), enquanto ventos de SW 
e WSW representaram juntos aproximadamente $22 \%$ das ocorrências. Quanto às velocidades dos ventos nesta estação meteorológica, os registros de maiores intensidade apresentam valor superior a $12,4 \mathrm{~m} / \mathrm{s}$, sendo estes provenientes do quadrante S-W (SW, SSW e S) durante o outono e inverno.

Tabela 4. Direção e frequência dos ventos com velocidade superior a 5,6 m/s nas diferentes estações do ano para a Estação Meteorológica de Torres (2002-2015).

Table 4. Direction and frequency winds with velocity over $5,6 \mathrm{~m} / \mathrm{s}$ at different seasons at Torres meteorological station (20022015).

\begin{tabular}{lcccc}
\hline \multirow{2}{*}{$\begin{array}{c}\text { Direção } \\
\text { Vento }\end{array}$} & \multicolumn{4}{c}{ Frequência (\%) } \\
\cline { 2 - 5 } & Verão & Outono & Inverno & Primavera \\
\hline $\mathrm{N}$ & 0,1 & 0,1 & 0,1 & 0,1 \\
$\mathrm{NE}$ & $\mathbf{4}$ & $\mathbf{1}$ & $\mathbf{1 , 8}$ & $\mathbf{7}$ \\
$\mathrm{E}$ & 0,3 & 0,1 & 0,1 & 0,2 \\
$\mathrm{SE}$ & 0,4 & 0,3 & 0,3 & 0,4 \\
$\mathrm{~S}$ & $\mathbf{2 , 2}$ & $\mathbf{3 , 1}$ & $\mathbf{4 , 8}$ & $\mathbf{4 , 4}$ \\
$\mathrm{SW}$ & 0,1 & $\mathbf{1 , 5}$ & $\mathbf{1 , 5}$ & 1 \\
$\mathrm{~W}$ & 0 & 0,3 & 0,4 & 0,2 \\
$\mathrm{NW}$ & 0 & 0 & 0 & 0 \\
\hline
\end{tabular}

$\mathrm{Na}$ estação da Lagoa Itapeva, durante o período de verão, observou-se a predominância dos ventos das direções ENE, NE, NNE e N com respectivamente $18,1 \%, 14,3 \%, 12,4 \%$ e $13,7 \%$ de frequência, enquanto os ventos do quadrante S-W, totalizam aproximadamente $17 \%$ de frequência. Já no outono, o vento de $\mathrm{N}$ é o mais frequente (18\%) seguido dos ventos de SSW (13\%). Apesar de menos frequentes que os ventos de $\mathrm{N}$, os ventos de SSW e das demais direções do quadrante S-W são os mais intensos para esta estação, atingindo velocidades superiores a $5,2 \mathrm{~m} / \mathrm{s}$ em aproximadamente metade das ocorrências deste quadrante. No período de inverno, os ventos dominantes permanecem nos mesmos quadrantes que nas estações de verão e outono, ; no entanto, a ocorrência de ventos da direção SW se destacam com $26 \%$, porém os ventos mais intensos tiveram frequência menor com relação ao total de ocorrências para este período. Mesmo assim, ventos com velocidades superiores a $12,3 \mathrm{~m} / \mathrm{s}$ foram registradas, sendo provenientes de SSW e S. No período de primavera os ventos do quadrante N-E voltam a predominar, tal como no período de verão, com ocorrência de respectivamente NE 19,5\%, N 17\%, NNE $13 \%$, ENE $10 \%$, seguidos dos ventos do quadrante S-W (SSW 13,3\%, SW 9\% e S 4,3\%). No período de primavera há significativa ocorrência de ventos de maiores intensidades, tanto de NE quanto de SSW.

$A$ análise da frequência direcional dos ventos predominantes (quadrantes N-E e S-W) registrados na estação de Torres (do INMET) ao longo dos meses do ano (Fig. 9), mostra que ventos capazes de remobilizar sedimentos (acima de $5 \mathrm{~m} / \mathrm{s}$ ) ocorrem em maior frequências no quadrante $S$-W entre os meses de abril e setembro (outono-inverno) e em maior frequência no quadrante N-E entre os meses de outubro e março (primavera e verão).

A distribuição de frequências (número de registros) mostra que os ventos do quadrante S-W com velocidades acima de $5 \mathrm{~m} / \mathrm{s}$ atuam na região durante o ano todo com um mínimo de $20 \%$ das ocorrências mensais (mínimo no mês de janeiro), enquanto que os ventos do quadrante N-E atuam na região predominantemente nos meses de primavera e verão, com ocorrências inferiores a $25 \%$ em três meses do ano: maio, junho e julho.

A predominância sazonal de ventos dos dois diferentes quadrantes reflete o caráter bimodal dos ventos desta região, juntamente com a intensidade dos ventos provenientes de cada direção, na sua atuação sobre a remobilização dos sedimentos da região extremo norte da PCRS. A ocorrência de ventos com intensidades acima de $5 \mathrm{~m} / \mathrm{s}$ provenientes de $\mathrm{S}$, SW e W se dá ao longo de todo o ano, com menores frequências em janeiro e fevereiro (20 e 38\% do total de ocorrências). Ventos com intensidades acima de $5 \mathrm{~m} / \mathrm{s}$ provenientes de $\mathrm{N}, \mathrm{NE}$ e E também ocorrem ao longo de todo o ano, porém com frequência muito menor nos meses de maio e junho (20 e 10\% do total de ocorrências).

\section{Discussão dos resultados}

Os registros de longo termo dos dados de vento das estações meteorológicas de Torres e Aeroporto permitem inferir os padrões climatológicos das direções e das intensidades dos ventos no extremo norte da PCRS. 0 primeiro aspecto que deve 
ser considerado na análise espacial dos resultados é a localização geográfica de cada uma das estações meteorológicas. A estação de Torres está localizada em uma região costeira a uma distância menor que $1 \mathrm{~km}$ da faixa litorânea. Já as estações SBTR e Lagoa Itapeva Central possuem distâncias da faixa litorânea respectivamente menor que 2,5 e $5 \mathrm{~km}$. A estação da Lagoa Itapeva Central apresenta os setores direcionais S-W e W-N bem próximos da barreira orográfica da formação Serra Geral, localizada a oeste da área de estudo. Estas características geográficas das estações implicam em alguns aspectos: (1) a direção dos ventos de maior intensidade registrados em cada uma das estações. A estação de Torres apresenta a ocorrência de ventos de maior intensidade provenientes de S; na estação SBTR as maiores intensidades não possuem uma única direção definida; e por fim, na estação da Lagoa Itapeva Central, as maiores intensidades ocorrem com maior frequência na direção SW; (2) as ocorrências das maiores intensidades coincidem com as direções livres de obstáculos orográficos em cada uma das estações. 0 relevo da região sugere que há uma zona de compressão das linhas de corrente dos fluxos na região sul do planalto Serra Geral, o que gera uma deflexão nas direções dos ventos provenientes de sul para sudoeste. Esta compressão do fluxo pode ocasionar o aumento da velocidade do vento nesta região por uma simples relação de conservação de massa. 0 que reforça a hipótese da influência do planalto são os registros de maiores intensidades de vento provenientes de WSW, SW e SSW na estação Lagoa Itapeva Central, e ocorrência muito menor de registro de ventos destas mesmas direções na estação de Torres (mais ao norte, e, portanto, mais protegida pela barreira orográfica a oeste). As maiores intensidades registradas podem ainda estar associadas ao posicionamento latitudinal de cada uma das estações meteorológicas, onde a estação localizada mais ao norte (Torres) registrou intensidade máxima de $14,5 \mathrm{~m} / \mathrm{s}$ e a estação mais ao sul (Lagoa Itapeva Central), aproximadamente $30 \mathrm{~km}$ de distância, teve o valor de 17,5 m/s registrado.

Segundo Gemiacki \& Ferodova (2006), os sistemas frontais atuam desde o sul do continente sul-americano (influência mais marcante) até latitudes mais baixas (onde geralmente chegam enfraquecidas). Apesar deste comportamento, não se pode atribuir o registro das maiores intensidades do vento na estação da Lagoa Itapeva somente à pequena diferença de latitude, mas sim considerar este aspecto de real potencial de contribuição para este fenômeno.

0 padrão de ventos obtidos pela análise dos dados da estação meteorológica de Torres, apesar de mostrar alguma pequena variação na frequência dos ventos, é bem similar aos valores encontrados por Tomazelli (1993) e Martinho (2008). Esta variação nos dados se deve, possivelmente, às diferentes séries históricas analisadas: enquanto os autores acima referidos utilizam uma série histórica de dados de um período de 13 anos (entre 1980 e 1993), o presente estudo fez a análise da uma série histórica de dados mais recente e com 14 anos (2002 a 2015). Além disso, a estação meteorológica de Torres estava localizada em um local diferente do atual, o que pode também ter gerado algumas diferenças nos dados coletados.

A análise das velocidades médias entre as duas estações que possuem períodos coincidentes (Torres e SBTR) apontam para maiores energias nos ventos registrados na estação SBTR, pois ao longo do período analisado os valores médios mensais são superiores aos da estação de Torres. 0 cálculo da média mensal considera todos os setores direcionais, e desta forma as componentes vetoriais das direções W e SW da estação SBTR contribuíram para as maiores velocidades médias calculadas para esta estação. 0 estudo de Martinho (2008) corrobora com essa análise e aponta maiores intensidades nos ventos de $\mathrm{W}$ para a estação localizada na Lagoa Itapeva Central. Apesar dos resultados sugerirem esta interpretação, temse como hipótese que a intermitência dos registros da estação Aeroporto, possivelmente contribui com maior diferença no cálculo das velocidades médias, pois há a possibilidade de períodos de velocidades extremas (máxima ou mínima) não terem sido registrados, consequentemente interferindo no cálculo da velocidade média. Mesmo assim, a variabilidade sazonal das intensidades dos ventos para o período de 13 anos analisados está marcada na variação temporal dos dados de ambas as estações. Esta variação é coincidente em ambas as séries representadas no gráfico. A diferença de velocidades médias máximas pode se justificar pela diferença de altitude ortométrica dos anemômetros nas duas estações meteorológicas analisadas. Cabe ressaltar que não há informação disponível quanto à altura dos sensores em relação à superfície.

A evolução de um sistema frontal ocorre de S para $\mathrm{N}$ e em seu deslocamento há a constante perda de energia cinética, por conta das características de cobertura da superfície. Como resultado, a proximidade da estação SBTR com a estação Lagoa Itapeva Central pode ter possibilitado a maior conservação de energia decorrente da menor resistência da água ao escoamento do vento. Conse- 
quentemente, ventos de maior intensidade podem ocorrer com maior frequência, o que, hipoteticamente, explicaria as maiores velocidade médias registradas para esta localidade. A variação sazon- al das intensidades dos ventos se mantem ao longo de toda série de dados analisadas para ambas as estações, como ventos médios mais intensos no inverno.

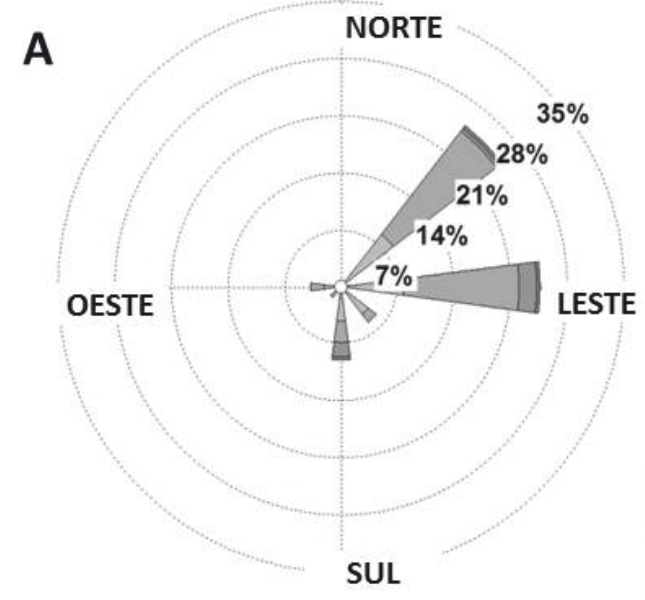

Verão 1999

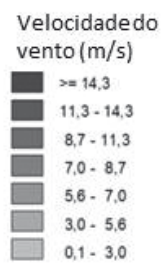

Calmaria: $29,91 \%$

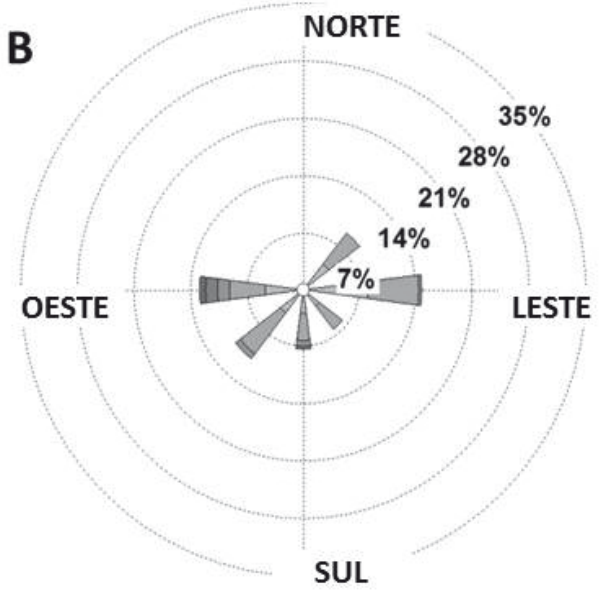

Outono 1999
Velocidadedo vento $(\mathrm{m} / \mathrm{s})$

$\square>14,3$

$11,3 \cdot 14,3$

$8,7 \cdot 11,3$

$7,0 \cdot 8,7$

$5,6 \cdot 7,0$

$3,0-5.6$
$0.1-3.0$

Calmaria: $39,05 \%$



Inverno 1999

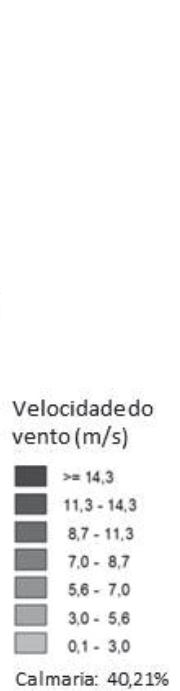



Primavera 1999
Velocidadedo vento $(\mathrm{m} / \mathrm{s})$

$>=14,3$
$11,3-14$ $11,3-14,3$
$87,11,3$ $7.0-8.7$ $7,0-8.7$
$5,6 \cdot 7,0$ $\square \begin{aligned} & 3.0-5.6 \\ & 0.1-3.3\end{aligned}$ Calmaria: $24,59 \%$

Figura 7. Rosa dos ventos mostrando a variação na direção e na frequência dos ventos nas quatro estações do ano na estação meteorológica de Torres, para o ano de 1999. A) Verão; B) Outono; C) Inverno e D) Primavera.

Figure 7. Wind rose showing variations in direction, frequency and velocity of winds during the four annual seasons at the Torres meteorological station, for the year 1999. A) Summer; B) Autumn; C) Winter and D) Spring.

Os resultados da análise sazonal para o ano de 1999 da estação Torres apresenta pequenas diferenças daqueles obtidos, para esta mesma estação meteorológica, da série histórica de 2002 a 2015. Uma das diferenças observadas é que durante o verão de 1999 a componente de E possui maior ocorrência. No período de outono, a componente de $\mathrm{W}$ é mais marcante, o que difere da série de 2002-2015. De forma geral, a grande diferença da série de longo termo e os ventos de 1999 é que para este ano os ventos de sul não ocorrem com grande frequência em todos os períodos, diferente do observado nas rosas de 2002-2015. As intensidades registradas apontam para maiores valores no período de inverno em ambos os períodos analisados para esta estação, com ocorrência de intensidades elevadas e frequentes provenientes do quadrante N-E, durante a primavera/verão. Este padrão de circulação observado está fortemente associado ao escoamento do Anticiclone do Atlântico Sul (AAS), principalmente para o período de verão. Segundo Andrioni (2010), o AAS é uma sistema de alta pressão semi-permanente existente no Atlântico Sul, o qual é responsável pelo 
bom tempo da costa brasileira.

Para o mesmo ano (1999), os resultados sazonais da estação meteorológica Lagoa Itapeva Norte possui um comportamento similar à estação Torres, com uma pequena diferença na frequência dos ventos de $\mathrm{N}$, o qual ocorreu com frequência relativa em todos os períodos daquele ano. $\mathrm{O}$ que mais chama a atenção na estação de Lagoa Itapeva Norte quando comparada à estação de Torres é a grande ocorrência de ventos provenientes de SW durante o inverno. Esta componente de direção SW pode estar associada à presença da Lagoa Itapeva, pois o espelho d'água da lagoa exerce menor resistência ao escoamento dos ventos superficiais e, consequentemente, não filtra as componentes menos energéticas, refletindo nos registros dessa estação meteorológica. 0 que reforça essa inferência é o fato de haver alto número de registros de

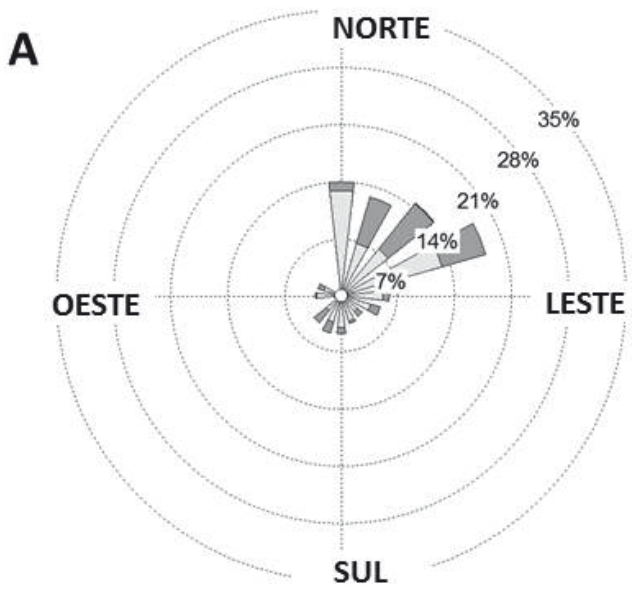

Verão 1999



Inverno 1999 ventos menores que $5,6 \mathrm{~m} / \mathrm{s}$ provenientes de $\mathrm{SW}$, os quais, provavelmente, seriam atenuados até a estação mais ao norte, Torres. Estas pequenas diferenças entre as duas estações analisadas sugerem uma variação espacial do comportamento do vento, tanto na frequência direcional quanto nas intensidades. No entanto, salienta-se que, quanto à extensão dos registros, a WMO (2015) recomenda 30 anos de dados para a determinação dos padrões climatológicos, assim nenhuma das séries possui a extensão necessária para uma caracterização mais rigorosa. Apesar destas características, em concordância aos objetivos do presente estudo, os dados analisados são suficientes para uma caracterização e, como já apontado anteriormente, corroboraram aos padrões descritos preconizado pela bibliografia disponível.


Figura 8. Rosa dos ventos mostrando a variação na direção e na frequência dos ventos no decorrer das estações do ano na estação meteorológica da Lagoa Itapeva Norte, para o ano de 1999. A) Verão; B) Outono; C) Inverno e D) Primavera. Adaptado de Lopardo (2002).

Figure 8. Wind rose showing variations in direction, frequency and velocity of winds during the four annual seasons at the Itapeva lake meteorological station. A) Summer; B) Autumn; C) Winter and D) Spring. Adapted from Lopardo (2002). 
A análise de frequência direcional dos ventos capazes de remobilizar sedimentos mostra a influência do regime de ventos bimodal da estação de Torres neste aspecto, visto que o numero de ocorrências para os diferentes quadrantes (N-E e S-W) varia ao longo do ano, porém a atuação de ambos os ventos é significativa durante o ano. 0 número de ocorrências de ventos acima de $5 \mathrm{~m} / \mathrm{s}$ mostra que durante metade do ano (outubro a março) predominam ventos do quadrante N-E e nos outros 6 meses (abril a setembro) predominam ventos quadrante S-W. Apesar da grande frequência de ventos dos dois quadrantes nos diferentes meses do ano, destaca-se que os ventos de $S$ possuem frequência significativa em todos os meses do ano, enquanto os ventos de NE ocorrem em frequência mais significativa nos meses de primavera e verão, e durante o inverno sua ocorrência diminui bastante.
Para corroborar os resultados, a mesma análise foi realizada para a série de dados de 1961 a 2002 (41 anos) da estação de Torres (que estava localizada em local distinto do atual, no Morro do Farol), e os resultados são similares, mostrando o mesmo padrão para o local avaliado, porém mostram ocorrência um pouco maior dos ventos de NE-E (com relação aos ventos de S-SW) no mês de setembro, evidenciando a entrada da primavera com ventos de NE. Destaca-se que no mês de setembro o numero de ocorrências entre ventos NE-E e S-SW é similar, sendo o único mês do ano em que isto ocorre. Este padrão bimodal de ventos com velocidades superiores a $5 \mathrm{~m} / \mathrm{s}$ corrobora as feições eólicas encontradas no campo de dunas de Itapeva, localizado no município de Torres, onde dunas reversas fazem parte da paisagem (Tomazelli et al., 2008).

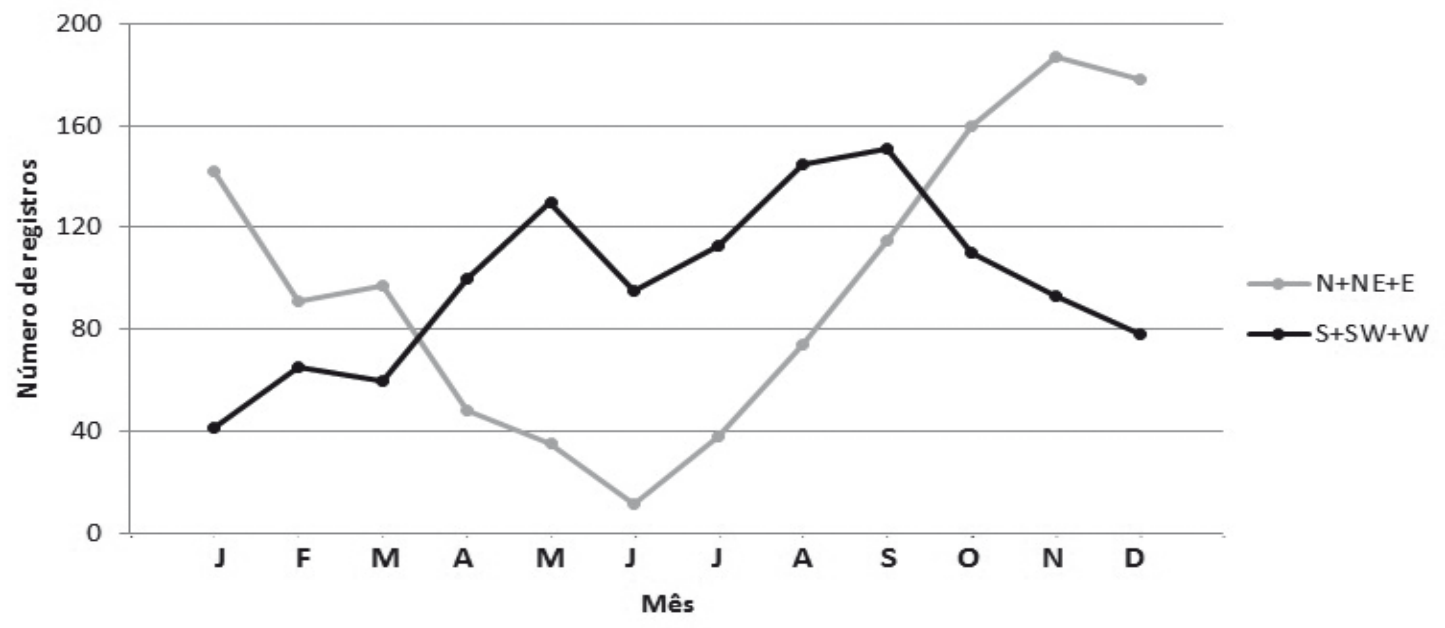

Figura 9. Frequência direcional dos ventos predominantes com velocidades acima de $5 \mathrm{~m} / \mathrm{s}$ na estação meteorológica de Torres (2002-2015).

Figure 9. Directional frequency of prevailing winds with velocities above $5 \mathrm{~m} / \mathrm{s}$ at Torres meteorological station (2002-2015).

\section{Conclusões}

A primeira intepretação quanto às características espaço-temporais dos ventos foi obtida por meio de interpretação dos diagramas de ocorrência conjunta. As informações providas por estas tabelas para as duas estações (Torres e Aeroporto) permitiram inferir que há diferenças nos padrões de escoamento do vento superficial para cada localidade. No entanto, diferenças não são significativas quando considerada a unidade direcional como sendo o quadrante. $\mathrm{O}$ outro conjunto de análises realizadas foram as rosas dos ventos de três localidades (Torres, Aeroporto e Lagoa Itapeva Central). A primeira inferência a se destacar é a maior ocorrência de ventos provenientes de NE na estação localizada mais ao norte (Torres) e ventos de SW mais frequente e intensos na estação mais ao sul (Lagoa Itapeva Central). No entanto, o que difere são as intensidades dos ventos em cada uma das estações. Desta forma, em todas as estações, as maiores ocorrências de ventos são provenientes do quadrante $\mathrm{N}-\mathrm{E}$. No entanto, quando analisadas as 16 seções direcionais, padrões de circulação local são evidenciados. Isto se deve ao aumento da discretização angular no registro a uma precisão de 22,5 graus, o que aumenta a capacidade de identificação das alterações da direção do vento pelas estações meteorológicas. Consequentemente, as influências da orografia e a proximidade do oceano ficam mais claras no registro de cada uma delas. Os estudos de Tomazelli (1993) e Martinho (2008) corroboram os resultados obtidos neste trabalho, indicando a influência fundamental da orografia 
nos ventos da região extremo norte da PCRS.

Ventos de maiores velocidades ocorrem no período de inverno em todas as estações meteorológicas. Do ponto de vista do comportamento espacial do vento, algumas conclusões são importantes destacar, tais como a rotação do sentido dos ventos preferencias, onde um giro de aproximadamente 30 graus ocorre da estação de Torres para a estação SBTR com uma deflexão de N-S para N-SW. Outra conclusão é que ao se deslocar para sul são maiores as chances de ocorrência de ventos de grandes intensidades. Conclui-se que a análise dos dados dos ventos das estações meteorológicas estudadas possibilitou identificar as principais características espaço-temporais dos ventos para a região de estudo.

Os desafios para a análise de séries históricas de registros de fenômenos ambientais são diversos. No presente estudo as características singulares de cada conjunto de dados, podem influenciar nos resultados das análises geradas e consequentemente na interpretação dos resultados. A avaliação da ocorrência das direções e intensidades dos ventos e a não sincronicidade dos dados medidos possivelmente influenciam nos resultados. Sinais de fenômenos de escala sinótica, tal como El Niño/LaNiña, que possam ter ocorrido em um dos períodos não coincidentes, podem marcar a série de dados de vento com ocorrência de ventos de direções e intensidades singulares, ou seja, fora do padrão médio esperado.

Existem diversas possibilidades de utilização dos resultados deste estudo, uma delas é a utilização como ferramenta de apoio a tomada de decisão para o planejamento ambiental. Como exemplo, cita-se a compreensão do comportamento morfodinâmico das dunas da região, um tema que exige o conhecimento dos padrões de circulação dos ventos. Neste caso, além da avaliação da frequência direcional dos ventos, é necessária uma avaliação mais detalhada da intensidade dos ventos, tamanho dos grãos e precipitação, por exemplo (Bagnold, 1941; Fryberger \& Dean, 1979).

Agradecimentos. Os autores agradecem ao $\mathrm{CNPq}$ pela bolsa de Doutorado da primeira autora (processo: 140770/2012-7), bem como à bolsista de Iniciação Científica Marina R. Fagundes, pelo auxílio na organização dos dados e confecção de alguns gráficos deste artigo.

\section{Referências}

Alves, E.D.L. \& Silva, S.T. 2011. Direção e velocidade do vento em uma floresta de transição Amazônia-Cerrado no norte de Mato Grosso, Brasil. Boletim Goiano de Geografia, 31(1): 63-74.

Andrioni, M. 2010. Influência de Forçantes Locais na Camada de Ekman Superficial do Talude Superior da Bacia de Santos. Curitiba, 193p. Dissertação de Mestrado, Programa de Pós-graduação em Engenharia de Recursos Hídricos e Ambiental, Universidade Federal do Paraná.

ASA. Applied Sciences Associates (South America). 2006. Modelagem do Descarte de Benzeno, Tolueno e Fenóis Totais na Água Produzida Descartada na Bacia de Campos. Disponível em: http://www.mma. gov.br/port/conama/processos/C657C5D3/Modelagem_BTF_BCampos.pdf. Acesso em: 23 jun. 2014.

Bagnold, R.A. 1941. The physics of blown sand and desert dunes. London, Methuen, 265p.

Braga, M.F.S. \& Krusche, N. 1998. Análise da Frequência das Velocidades do Vento em Rio Grande, RS. In: CONGRESSO BRASILEIRO DE METEOROLOGIA, 10., 1998, Brasília. Anais... Instituto Nacional de Pesquisas Espaciais - INPE. 6p. Disponível em: <http:// www.cbmet.com/>. Acesso em: ago. 2015.

Brito-Costa, G. 2009. Análise espacial e temporal do vento no Estado de Alagoas. Alagoas, 126p. Dissertação de Mestrado, Programa de Pós-Graduação em Meteorologia, Instituto de Ciências Atmosféricas, Universidade Federal de Alagoas.

Camargo, O.A. \& Silva, F.J.L. 2002. Atlas Eólico: Rio Grande do Sul. Porto Alegre, SEMC-Secretaria de Energia Minas e Comunicações. 70 p.

Cardoso, L.S. 2001. Variações da estrutura planctônica da Lagoa Itapeva (Sistema Lagunar Costeiro do Rio Grande do Sul) em função da hidrodinâmica. Porto Alegre, 466p. Tese de Doutorado, Programa de Pós-Graduação em Engenharia de Recursos Hídricos e Saneamento Ambiental, Instituto de Pesquisas Hidráulicas, Universidade Federal do Rio Grande do Sul.

Cardoso, L.S., Silveira, A.L.L. \& Motta Marques, D.M.L. 2003. A ação do vento como gestor da hidrodinâmica na Lagoa Itapeva (Litoral Norte do Rio Grande do Sul-Brasil). Revista Brasileira de Recursos Hídricos, 8(3): 5-15.

Costa, G.B. \& Lyra, R.F.F. 2012. Análise dos padrões de vento no estado de Alagoas. Revista Brasileira de Meteorologia, 27(1): 31-38.

Da Silva, J.K.A. 2007. Caracterização do vento e estimativa do potencial eólico da região de tabuleiros costeiros (Pilar, Alagoas). Alagoas, 79p. Dissertação de Mestrado, Programa de Pós-Graduação em Meteorologia, Instituto de Ciências Atmosféricas, Universidade Federal de Alagoas.

Dillenburg, S.R., Barboza, E.G., Tomazelli, L.J., Hesp, P.A., Clerot, L.C.P., Ayup-Zouain, R.N., 2009. The Holocene Coastal Barriers of Rio Grande do Sul. In: Dillenburg, S.R., Hesp P.A. (Eds.), Geology and Geomorphology of Holocene Coastal Barriers of Brazil. Springer, Lecture Notes in Earth Sciences 107, p. 53-91.

Favera, A.C.D., Luiz, E.W., Schuch, N.J., Martins, F.R. \& Pereira, E.B. 2012. Potencial Eólico no Rio Grande Do Sul - Distribuição Estatística dos Ventos na Região Central do Estado. Revista Geográfica Acadêmica, 
6(1): 38-51.

Fryberger, S.G. \& Dean, G. 1979. Dune forms and wind regime. In: McKee, E.D. (Ed.). A Study of Global Sand Seas. USGS, Professional paper 1052:137-169.

Fuentes, E.V., Bitencourt, D.P. \& Fuentes, M.V. 2013. Análise da velocidade do vento e altura de onda em incidentes de naufrágio na costa brasileira entre os estados do Sergipe e do Rio Grande do Sul. Revista Brasileira de Meteorologia, 28(3): 257-266.

Gemiacki, L. \& Ferodova, N. 2006. Atuação de um sistema frontal na estação seca do nordeste do Brasil. In: CONGRESSO BRASILEIRO DE METEOROLOGIA, 14., 2006, Florianópolis. Anais... Florianópolis, Instituto Nacional de Pesquisas Espaciais - INPE, 6p. Disponível em: <http://www.cbmet.com/>. Acesso em: ago. 2015.

Grimm, A.M., Ferraz, S.E.T. \& Gomes, J. 1998. Precipitation anomalies in Southern Brazil associated with El Niño and La Niña events. Journal of Climate, 11: 2863-2880.

Homsi, A. 1978. Wave climate in some zones off the Brazilian coast. In: INTERNATIONAL CONFERENCE ON COASTAL ENGINEERING, 16., 1978. Proceedings... Hamburg, Germany, American Society of Civil Engineers, p.114-133. DOI: 10.1061/9780872621909.007

INMET. Instituto Nacional de Meteorologia (Brasil). 2015. Normais Climatológicas do Brasil 1961-1990. Disponível em: <http://www.inmet.gov.br/>. Acesso em: 03 mai. 2015.

Kim, I.S. 1998. Análise da variabilidade e variação dos índices El Niño, Oscilação Sul e chuvas nos estados do Rio Grande do Sul e Santa Catarina do Brasil. In: CONGRESSO BRASILEIRO DE METEOROLOGIA, 10., 1998, Brasília. Anais... Instituto Nacional de Pesquisas Espaciais - INPE, 5p. Disponível em: <http:// www.cbmet.com/>. Acesso em: jun. 2015.

Kousky, V.E. \& Cavalcanti, I.F.A. 1984. Eventos Oscilação Sul - El Niño: Características, Evolução e Anomalias de Precipitação. Ciência e Cultura, 36(11): 18881899.

Lopardo, N. 2002. Estudo hidrodinâmico e correlação com sólidos suspensos e turbidez na lagoa Itapeva do litoral norte do estado do Rio Grande do Sul. Porto Alegre, 168p. Dissertação de Mestrado, Programa de Pós-Graduação em Engenharia de Recursos Hídricos e Saneamento Ambiental, Instituto de Pesquisas Hidráulicas, Universidade Federal do Rio Grande do Sul.

Martinho, C.T. 2008. Morfodinâmica e evolução de campos de dunas transgressivos quaternários do litoral do Rio Grande do Sul. Porto Alegre, 216p. Tese de Doutorado, Programa de Pós-Graduação em Geociências, Instituto de Geociências, Universidade Fede-

Manuscrito 605

Editores: Iran C. S. Corrêa \& Paulo A. Souza. ral do Rio Grande do Sul.

Martinho, C.T., Hesp, P. \& Dillenburg, S.R. 2010. Morphological and temporal variations of transgressive dunefields of the northern and mid-littoral Rio Grande do Sul coast, Southern Brazil. Geomorphology, 117(1-2): 14-32.

Morais, G.M., Sobrinho, J.E., Santos, W.O., Costa, D.O., Silva, S.T.A. \& Maniçoba, R.M. 2014. Caracterização da velocidade e direção do vento em Mossoró/RN. Revista Brasileira de Geografia Física, 7(4): 746-754.

Munhoz, F.C. \& Garcia, A. 2008. Caracterização da velocidade e direção predominante dos ventos para a localidade de Ituverava-SP. Revista Brasileira de Meteorologia, 23(1): 30-34.

Nimer, E. 1977. Climatologia do Brasil. 2a. ed., Rio de Janeiro, IBGE - Departamento de Recursos Naturais e Estudos Ambientais, 421p.

Pearce, K.I. \& Walker, I.J. 2005. Frequency and magnitude biases in the 'Fryberger' model, with implications for characterizing geomorphically effective winds. Geomorphology, 68: 39-55.

Reis, B.G. \& Berlato, M.A. 1972. Aspectos gerais do clima do Estado. Porto Alegre, Instituto Nacional de Colonização e Reforma Agrária, v. 1, 187 p.

Silva, J.B., Zanusso, J.F. \& Silveira, D.L.M. 1997. Estudo da velocidade e direção dos ventos em Pelotas, RS. Revista Brasileira de Agrometeorologia, 5(2): 227-235.

Tomazelli, L.J. 1990. Contribuição ao estudo dos sistemas deposicionais holocênicos do nordeste da província costeira do Rio Grande do Sul, com ênfase no sistema eólico. Porto Alegre, 270p. Tese de Doutorado, Programa de Pós-Graduação em Geociências, Universidade Federal do Rio Grande do Sul.

Tomazelli, L.J. 1993. O Regime de ventos e a taxa de migração das dunas eólicas costeiras do Rio Grande do Sul, Brasil. Pesquisas, 20(1): 18-26.

Tomazelli, L.J., Dillenburg, S.R. \& Villwock, J.A. 2000. Late quaternary geological history of Rio Grande do Sul coastal plain, Southern Brazil. Revista Brasileira de Geociências, 30(3): 474-476.

Tomazelli, L.J., Dillenburg, S.R., Barboza, E.G. \& Rosa, M.L.C.C. 2008. Geomorfologia e Potencial de Preservação dos Campos de Dunas Transgressivos de Cidreira e Itapeva, Litoral Norte do Rio Grande do Sul. Pesquisas em Geociências, 35(2): 47-55.

Tubelis, A. \& Nascimento, F.C.L. 1984. Meteorologia descritiva: Fundamentos e aplicações brasileiras. São Paulo, Nobel, 374p.

WMO. World Meteorological Organization. 2015. World Climate Programme (WCP). Disponível em: < http:// www.wmo.int/pages/prog/wcp/ccl/faqs.php >. Acesso em: 12 out. 2015. 
